\title{
LA INFANCIA DE LA PERIFERIA: RELATO DE UNA EXPERIENCIA
}

The childhood of the periphery: a story of an experience

A infância da periferia: relato de uma experiênci

\section{Daniel Hincapié Bedoya}

Grupo de investigación Prácticas Corporales, Sociedad, Educación - Currículo [PES] de la Universidad de Antioquia [Col]. Cel. +57 313732 3454. Correo electrónico: danbedoya77@,hotmail.com

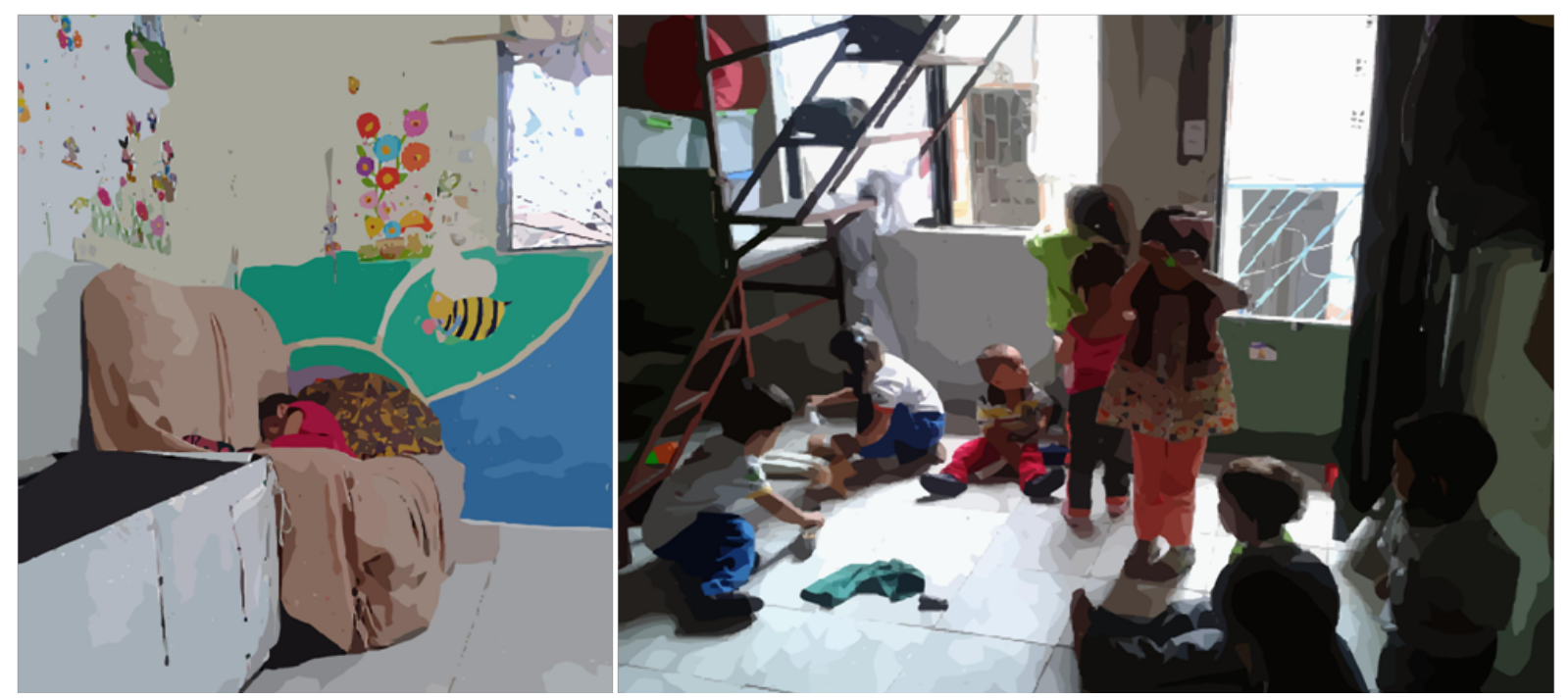

Ilustración 1 Al interior de un Hogar Comunitario.

\section{Resumen}

Relato descriptivo que da cuenta de la sistematización de una experiencia de intervención pedagógica al interior de los hogares comunitarios del Instituto Colombiano de Bienestar Familiar. La intervención se desarrolla desde la política pública de atención integral a la primera infancia Buen Comienzo del municipio de Medellín en asocio con oferentes privados, desde una modalidad de intervención denominada itinerante, estrategia utilizada para movilizar equipos interdisciplinarios conformados por profesionales de la salud y la educación hacia los barrios populares de la ciudad. Con la reflexión - Infancia de la 
periferia - se intenta problematizar el lugar de la infancia en lo social, el lugar del profesor de Educación Física en estos ámbitos de intervención y los propósitos sociales cuando son ejecutados por la vía de la tercerización laboral y las alianzas publico privadas.

Palabras Clave: infancia, hogar comunitario, itinerante, periferia.

\begin{abstract}
Descriptive report that gives an account of the systematization of an experience of pedagogical intervention within the community homes of the Colombian Institute of Family Welfare. The intervention takes place from the public policy of integral attention to early childhood Good Start of the municipality of Medellín in partnership with private providers, from a mode of intervention called itinerant, a strategy used to mobilize interdisciplinary teams made up of professionals in health and education to the popular neighborhoods of the city. With the reflection - Childhood of the periphery - it is tried to problematize the place of the childhood in the social, the place of the professor of Physical Education in these fields of intervention and the social purposes when they are executed by means of the outsourcing and the alliances public-prívate.
\end{abstract}

Keywords: Childhood, Community Home, Itinerant, Periphery

\title{
Resumo
}

Trata-se de um relato descritivo que dá conta da sistematização de uma experiência de intervenção pedagógica ao interior dos lares comunitários do Instituto Colombiano de Bem - Estar Familiar. A intervenção se desenvolve desde a política pública de atenção integral à primeira infância Bom Começo do município de Medellín em articulação com entidades privadas, desde uma modalidade de intervenção denominada itinerante, estratégia utilizada para mobilizar grupos interdisciplinares formados por profissionais da saúde e a educação para os bairros populares da cidade. Com a reflexão - "infância da periferia" - tenta-se problematizar o lugar da infância no social, o lugar do professor de Educação Física nestes âmbitos de intervenção e os propósitos sociais quando são executados pela via da terceirização laboral e as alianças público-privadas.

Palavras Chave: infância, Lar Comunitário, Itinerante, Periferia. 
“... también el lobo tiene dos y más de dos almas dentro de su pecho de lobo, y quien desea ser un lobo incurre en el mismo olvido que el hombre de aquella canción: “ffeliz quien volviera a ser niño!” el hombre simpático pero sentimental, que canta la canción del niño dichoso, quisiera volver también a la naturaleza, a la inocencia, a los principios, y ha olvidado por completo que los niños no son felices en absoluto, que son capaces de muchos conflictos, de muchas desarmonías, de todos los sufrimientos." [El lobo estepario. Hermann Hese.]

Con una frecuencia naturalizada y naturalizante olvidamos día a día, o mejor, convertimos en olvidados a muchos de los niños y las niñas de la ciudad que no contaron con la suerte de ser esas niñas y niños de manual, de ser los dueños de una imagen que nos fueron enseñado a desear y que en ese ejercicio nos fue invisibilizando también nuestro mismo rostro infantil, poniendo en su lugar el retrato de un niño blanco, varón, inocente y feliz; del que nos convencieron de niño promedio, estándar e ideal.

Decir que la primera infancia es una etapa o periodo trascendental en el desarrollo de cada ser humano, es una afirmación tan apalabrada como ignorada. Lugar común y pretexto conveniente de la política oficial, muletilla y caballito de campaña que sirve de plataforma electoral de quienes, en medio de nuestra doble moral, encuentran un lugar para el ascenso burocrático; demagogia academicista de las y los promulgadores del desarrollo humano y cliché ciudadano que en medio de la naturalización cotidiana revierte, el derecho de ser de las niñas y niños, en un objeto más de instrumentalización y vulneración. Pornoinfancia ${ }^{l}$ que se alimenta con el pudor que produce la mirada exotizada.

En este texto se pretende, en un intento de reflexión, visibilizar la infancia de la periferia, categoría con la que se procura dar cuenta del lugar que hoy día ocupa la niñez en lo social, más allá de una referencialidad geográfica en la ciudad. Se expone, a partir de un

1 Pornoinfancia: término que he introducido para señalar el negocio asociado a la utilización de la infancia como instrumento lastimero; podría decirse que es una objetivación de la infancia desde una mirada voyerista. Este término está inspirado en el concepto de PORNOMISERIA desarrollado por los cineastas colombianos Carlos Mayolo y Luis Ospina quienes introdujeron el término para nominar el negocio desarrollado alrededor de la miseria a través de la industria cinematográfica. En la película Agarrando Pueblo se puede ver la crítica al cine miserabilista desde el cine mismo. 
relato descriptivo, una práctica de intervención pedagógica en la que me encuentro como profesor [educador físico] novel ante mi primera oportunidad laboral en un programa gubernamental, que en medio de la tercerización laboral, pasa a ser agenciado por la institucionalidad privada. La experiencia acontece al interior de un programa de atención integral a la primera infancia desarrollado bajo una modalidad de intervención itinerante en la que el profesor debe desplazarse y aventurarse día a día, con el peso de su saber, en una ruta pedagógica por los barrios populares de la ciudad; viaje que permite, en el encuentro con la niñez periférica descubrir y de paso cuestionar la marginalidad de su existencia en la ciudad y en lo social.

Se trata entonces de la sistematización, del relato de una experiencia, en el sentido que le otorga Larrosa (2006) como "eso que me pasa"; es decir, el modo en que esta experiencia laboral me ha afectado, provocándome algunas preguntas y reflexiones, fundamentalmente con lo que tiene que ver con mi condición de profesor de educación física y con los sentidos de mi ejercicio profesional en relación con las personas, para este caso, en relación con la infancia y las comunidades de sectores marginados de la ciudad. Parto de cuestiones como: ¿Hasta qué punto hemos superado la representación idealizada o divinizada $^{2}$ de la infancia? ¿Responden estos programas a políticas con enfoque social de derecho o son producto de temores frente a la representación criminal de infancias ${ }^{3}$ y familias estigmatizadas por su condición de clase social? ¿Qué hago y qué debo hacer [como profesor de EF] en un programa de atención integral a la primera infancia que se moviliza por los sectores populares de la ciudad? ¿Para qué me han contratado realmente? ¿De qué discursos o políticas es subsidiario mi saber? Preguntas que han emergido en el trasegar la ciudad y visitar-encontrar una infancia que solo conocía como abstracción.

\section{Contexto. La Medellín de la infancia}

La experiencia aquí relatada aconteció en tres comunas ubicadas al nororiente de la ciudad de Medellín, zona con una alta presencia de conflicto social, desempleo, pobreza e

2 Frente a esta representación ver los aportes de Philippe Ariès [1987], específicamente lo desarrollado en el texto: El niño y la vida familiar en el antiguo régimen.

3 Para ampliar esta idea, se puede leer la clasificación y caracterización de subjetividades infantiles realizada por Laiton y Olmos [2013] en su tesis de maestría. Subjetividades que según las investigadoras contribuyeron a la generación de un sentimiento de protección y cuidado de la infancia en Colombia entre 1960 - 1990. 
indiferencia estatal; tres barrios, de tres comunas con una realidad compartida, la de la niñez periférica.

Ya es disiente la nominación que recibe en el informe de la personería de Medellín el apartado sobre infancia: Sujetos de derecho y objeto de vulneración. Nominación que introduce la realidad a la que se ve enfrentada la niñez en esta ciudad, según el informe el 6\% de los homicidios registrados en el 2015 corresponden a crímenes contra la infancia, con todo y que esta cifra representa una reducción del 55,4\% en el periodo 2012-2015, reducción que, según este informe, podría estar asociada al pacto o tregua entre las bandas armadas de la ciudad, situación que de paso ha generado una alta manipulación de la niñez en el conflicto intraurbano a través del reclutamiento de menores para la guerra, el expendio y consumo de alucinógenos y la explotación sexual comercial. El mismo informe denuncia que de las 512 desapariciones reportadas en el año 2015 el 30,09\% corresponde a niñas, niños y adolescentes.

El derecho a la integralidad y libertad sexual de la infancia, para el año 2015 fue el más vulnerado en la ciudad, siendo este grupo etario objeto del 73\% de los casos reportados como abuso, con el agravante que de estos casos el 39,9\% corresponde a niñas y niños entre los 0 y 9 años de edad. Estas cifras indican que éste es un flagelo que viene en aumento en relación con los indicadores de años anteriores, el informe plantea que uno de los detonantes de esta situación ha sido el deterioro de la familia como entorno protector y su constitución progresiva en un foco de violencia y maltrato sexual (Personería de Medellín, 2016).

En este contexto de ciudad, se estuvo desarrollando el programa Buen Comienzo de la alcaldía de Medellín, programa dirigido a la atención integral de la primera infancia, la acción aquí referenciada tomó como estrategia la movilidad y el desplazamiento de los agentes educativos (Educadora infantil, educador(a) físico, nutricionista, psicóloga) hacia los barrios populares y los hogares comunitarios [En adelante HC] de la ciudad, bajo una modalidad de intervención denominada itinerante. Oportunidad para reconocer en sitio la dirección u orientación de las políticas públicas que desde el papel se trazan sobre la infancia. A continuación, se presenta una caracterización de este programa de atención 
integral a la primera infancia desde la modalidad itinerante del programa Buen Comienzo de la ciudad de Medellín.

\begin{tabular}{c|l|}
\cline { 2 - 3 } $\begin{array}{c}\text { De cero a siempre } \\
\text { [Política Pública] }\end{array}$ & $\begin{array}{l}\text { CONTEXTO/DECRIPCIÓN } \\
\text { Programa nacional, estrategia de atención integral a la primera infancia [de } \\
\text { [Esposa del presidente colombiano] desde el año 2011. Esta estrategia intenta } \\
\text { articular y aunar voluntades desde el sector privado, el sector público, algunas } \\
\text { ONG's y algunas organizaciones de la sociedad civil con la intención de } \\
\text { gestionar recursos que garanticen la atención integral de los niños y niñas del } \\
\text { país de los estratos } 1 \text { 1, 2 y 3 en sus primeros 5 años de vida y de las madres } \\
\text { gestantes. En el año 2016 este programa es aprobado y elevado a política de } \\
\text { Estado de forma permanente. }\end{array}$ \\
\hline \multirow{2}{*}{$\begin{array}{c}\text { Muen Comienzo } \\
\text { de la política] }\end{array}$} & $\begin{array}{l}\text { Programa de la alcaldía de Medellín orientado a la atención de los niños, niñas } \\
\text { y sus familias durante los primeros cinco años de vida desde la articulación } \\
\text { entre la secretaría de educación municipal, la secretaría de inclusión social y } \\
\text { familia y salud, el instituto de deporte y recreación de la ciudad [INDER], el } \\
\text { instituto colombiano de bienestar familiar [ICBF], el ministerio de educación } \\
\text { nacional [MEN] y el sector privado. Este programa se articula a la política } \\
\text { pública nacional de cero a siempre. }\end{array}$ \\
\hline
\end{tabular}

${ }^{4}$ Los estratos socioeconómicos corresponden a una clasificación social de acuerdo a la información recolectada por el departamento nacional de estadística en relación con la posesión y el valor de bienes inmuebles y predios, esta clasificación funciona como indicador para asignar el precio a los impuestos y servicios públicos. En Colombia la estratificación socioeconómica está valorada en una escala de 1 a 6 , así: estrato 1: bajo - bajo; estrato 2: bajo; estrato 3: medio - bajo; estrato 4: medio; estrato 5: medio - alto y estrato 6: alto. 


\section{Modalidad itinerante}

del programa Buen

Comienzo

[Equipo

interdisciplinario]

Hogares comunitarios

[HC]
Estrategia del programa Buen Comienzo de la ciudad de Medellín que busca garantizar la atención integral a la primera infancia de los sectores populares de la ciudad a partir de la movilización, hacia los barrios y los HC, de equipos interdisciplinarios de profesionales de las áreas de la salud y la educación [psicología, nutrición, educación física y pedagogía]. Este equipo de profesionales sostenía encuentros pedagógicos con las madres comunitarias y los niños(as) de los $\mathrm{HC}$ con diferente periodicidad de acuerdo al profesional, discriminados así: La agente educativa educadora infantil visitaba el hogar comunitario cuatro veces al mes, un día por semana; el o la agente educativa educadora física dos veces al mes, un día cada quince días; y la agente educativa nutricionista o psicóloga(o) una vez cada mes.

El programa impactaba todas las comunas de la ciudad en las que se cuenta con HC del ICBF [Instituto Colombiano de Bienestar Familiar], que corresponden en su gran mayoría a sectores de estratos sociales 1,2 y 3 . En lo que respecta a esta experiencia, las comunas aquí referenciadas corresponden al sector nororiental de la ciudad, barrios de estratos 1,2 y 3 , con altos índices de pobreza, desempleo y conflicto social.

Casas de familia, vecinos de los mismos barrios, hogares habitados por familias constituidas por parejas maritales, hijos, nietos, en algunos casos tíos y abuelos. Estos hogares están avalados para recibir y atender hasta 13 niños. Las casas son construcciones hechas por los propios dueños y habitantes, sin mucho conocimiento arquitectónico y menos aun sin prever las condiciones físicas y de seguridad que debe tener un lugar para atender la niñez. Casas con poco espacio, generalmente se dispone de una pequeña sala en la que los niños y niñas del hogar deben permanecer sin la opción de moverse hacia otros lugares de la casa, estas salas [salón] habitualmente están contiguas a la cocina, espacio que ofrece mayor control y supervisión por parte de la madre comunitaria. Hogares con escasas condiciones de privacidad e intimidad; hogares/escuelas/"guarderías" que a cambio de "seguridad" material se ofrecen como lugares llenos de afecto, calor, protección y cuidado. 
La madre comunitaria

Padres, madres y/o cuidadoras de los niños y niñas
Señoras que en su gran mayoría son cabezas o jefas de hogar, adultas mayores que han transformado su casa en $\mathrm{HC}$, históricamente su labor se inicia desde una acción voluntaria para atender la infancia de los sectores marginados. Desde finales de los años 70 e inicios de los años 80 las madres comunitarias vienen luchando por garantías sociales y por la formalización de su labor. Sólo hasta el año 2014 consiguieron, en medio de paros y movilizaciones sociales, lograr este reconocimiento por parte del Estado colombiano, sin embargo, su historia sigue siendo la de una pelea por lograr reconocimiento. Muchas de estas madres comunitarias no cuentan con su nivel de escolaridad completo y han venido capacitándose, algunas ya cuentan con la formación técnica en educación infantil. Para ampliar información se puede revisar la columna de opinión "una mano para las madres comunitarias"5 (Henao, 2017. En línea).

Niñez de 0 a 5 años, hijas e hijos de familias trabajadoras o de familias que no cuentan con las condiciones materiales [básicamente la alimentación] para atender a sus hijos(as) durante todo el día en el hogar.

Habitantes de estas comunas. Se dedican fundamentalmente a trabajos informales: cocineras y cocineros en restaurantes o sitios de comidas rápidas, peluqueras, mecánicos, empleadas domésticas con contratos por días, conductores, oficiales de construcción, confeccionistas, vendedores ambulantes, rebuscadores [vendedores ambulantes de música, películas, ollas, ropa...], trabajadores y trabajadoras del día y de la noche, calle arriba - calle abajo. [Información recolectada en campo en actividad de caracterización de familias].

Cuadro 1. Contexto de la intervención del programa itinerante de Buen Comienzo.

Se reconoce una interesante articulación intersectorial y una apuesta gubernamental por garantizar la atención integral a la primera infancia en la ciudad de Medellín; una política de gobierno municipal que se articula a una política de Estado y a su vez el diseño de una estrategia móvil que llega a los $\mathrm{HC}$ del Instituto Colombiano de Bienestar Familiar [ICBF] mediante la movilización de profesionales por los barrios, estrategia de intervención itinerante que podría representar una solución frente a barreras o privaciones de acceso para

\footnotetext{
${ }^{5} \mathrm{http}: / /$ www.elcolombiano.com/opinion/columnistas/una-mano-para-las-madres-comunitarias-AI5903389
} 
la atención integral y la educación de la primera infancia, asuntos como el espacio, la seguridad o el desplazamiento de los niños y niñas a centros educativos que se encuentran distanciados de los HC podrían repararse desde el fortalecimiento de programas como este.

Se reconoce una política y un dispositivo potente para garantizar la atención/educación de la niñez que crece en entornos marginados socialmente, la experiencia en campo permite comprender que la atención integral y la educación de la infancia en estos lugares no llegará desde innovaciones o respuestas mesiánicas sino que depende del reconocimiento, la mejora y el fortalecimiento de estrategias, programas y acciones que a fuerza de voluntad se vienen desarrollando; proyectos que ya están siendo, lugares como los $\mathrm{HC}$ que entre el silencio y el olvido han criado y educado a la infancia periférica de la ciudad y del país durante casi cuatro décadas.

\section{Había una vez un Hogar Comunitario [HC]}

22 de septiembre de 2016, son las siete y cuarentaicinco de la mañana, doña Fabiola [madre comunitaria] y yo conversamos mientras esperamos a que lleguen los niños y niñas. De manera espontanea, sin dirigir la conversación hacia el tema doña Fabiola empieza a contarme lo siguiente:

“esto por acá era muy caliente, me acuerdo, una vez nos cayó un petardo justo ahí en la puerta, ¡casi me deja sorda, casi me mata!”, - divaga un poco y sigue con más, cómo desahogándose o previniéndome tal vez - “allí abajito, en la 38 [calle 38] un día descuartizaron un muchacho y se lo mandaron en un costal a su mamá, al medio día le mandaron la cabeza con una nota que decía: Ahí le mando a su hijo pa que haga un sancocho ${ }^{6}$ con él" - llega un silencio acompañado de una mirada perdida, un suspiro y extrañamente algo de risa [risa nerviosa, risa que quiere tranquilizarme un poco] - "en el 2000 [año] cuando tenía el hogar comunitario por acá, tenía muy poquitos niños, esto estaba prendido [alto conflicto armado] por todos lados [señala los puntos cardinales alrededor de su casa], un día iba para una reunión, iba con tres niños cuando me encontré con unos muchachos que llevaban unas armas así [me ilustra gesticulando con sus manos], apenas me hicieron seña de que corriera y ahí

\footnotetext{
${ }^{6}$ Comida típica, tradicional de la región.
} 
mismito se prendió" - otro silencio, corto silencio, "los niños aprenden todo... y muchos crecen en familias dedicadas a esto [a las armas, micro-tráfico]” - Doña Fabiola se levanta, sonríe y se va hacia la cocina, mientras esperamos a los niños y niñas que ya no tardan en llegar.

En medio de esta realidad hecha paisaje aparece la puerta abierta de un hogar que con calor y olor comunitario adopta a los más pequeños e indefensos, el nombre no es, a diferencia de lo que pasa con muchos otros proyectos, una arandela de adorno, aquí cuando se habla de $\mathrm{HC}$ se siente de hecho que un lugar así no podría llamarse distinto. Estos lugares, que bien toman el nombre de hogares, representan para muchos niños y niñas el espacio más seguro al que tienen acceso en sus barrios y podrían representar una real oportunidad para cambiar los pasos que su entorno más próximo ofrece como camino todos los días. En medio de este contexto hostil, el HC se abre camino entre dos opciones: de un lado cumplir con una tarea de selección y aprehensión crítica de su entorno o de otro lado fundirse con sus alrededores, porque como plantea Trilla "la escuela más arraigada al medio más degradado tendrá todas las posibilidades de convertirse en la escuela también más degradada" (2004: 320). Siguiendo a Trilla, se dirá que hay ocasiones en que la escuela [para este caso el $\mathrm{HC}$ ] debe tomar distancia y operar como espacio protector; cerrar la puerta esperando abrir la oportunidad para que exista una realidad otra. No todos los alrededores escolares pueden apropiarse como espacios "simbióticos" o idóneos para los proyectos educativos y no todas las escuelas, bajo su lógica cerrada o "amurallada", representan cautiverio. A veces cerrar la puerta es abrirla.

\subsection{Entrando a un Hogar Comunitario [HC]. EI caso de "Ojitos Lindos"}

Llegar al HC “ojitos lindos 7" es como llegar a la vecindad del chavo, se ingresa por una portada metálica que te va introduciendo en un callejón rodeado de muchas pequeñas casas,

es como un barrio dentro de un barrio, vecindario constituido por viviendas que se van levantando y te obligan a mirar hacia arriba, casas a las que se asciende a través de escalas que se van perdiendo o cerrando en su estructura de caracol, forma que ya sugiere, en su

7 Nombre ficticio. 
espiral profunda y concéntrica, el carácter acogedor, amable, lúdico y colorido del HC que te sorprende y te encuentra, primero con el olor y luego con su sabor.

Un aroma a chocolate y canela, que se va confundiendo con otros olores de cocina, te van diciendo que has llegado. Las casas pequeñas y cerradas dejan salir todos los olores de los alimentos del día - que desde temprano se cocinan y que se han mezclado -; olor a hogar, aroma comunitario que se escapa, gas que se expande con la apertura de la puerta y las ventanas que, de par en par dan la bienvenida; vapor, olor, aroma que recibe a la niñez que va entrando cautivada por el olor y el calor de una profesora que a falta de título acartonado le han nombrado madre.

Esta madre, sabe muy bien lo que pesa ese apellido de "comunitaria", lo lleva sobre su espalda en medio de una sociedad patriarcal que en su miedo ha negado e invisibilizado la labor, el rol y el lugar de la mujer en la vida pública, contexto en el que paradójica e irónicamente estas madres comunitarias se han constituido, a la fuerza, en las cabezas de hogar, las jefas de una casa transformada en $\mathrm{HC}$ en el que se brinda a niñas y niños protección, educación y afecto. Decir madres comunitarias es tratar de entender que son las segundas mamás, en ocasiones las primeras y a veces las únicas madres de distintas generaciones; de la infancia y la juventud de barrios enteros.

Aquí, en “ojitos lindos”, los niños y niñas e incluso sus padres y madres llaman tía a doña Magola - la madre comunitaria -, expresión que en nuestro contexto se convierte en una muestra contundente de la cercanía y confianza que puede generar una madre comunitaria. La tía, como es llamada a la madre comunitaria en este $\mathrm{HC}$, hace las veces de profesora, mamá, papá, amiga y en ocasiones hasta de una niña más; siempre atenta y dispuesta para alimentar, enseñar, aconsejar, corregir, acariciar y jugar.

Pero el HC es mucho más que eso, quiero decir mucho más de lo que puedo describir, no podría representarse como una escuela pues tiene mucho de hogar, no es tampoco un hogar pues tiene mucho de escuela y no podría dibujarse como una guardería pues no es un parqueadero de niñas [os]; es algo de las tres cosas y ninguna en particular, espacio que se mueve entre la escolarización y la acogida y que aún no hemos dimensionado totalmente. 


\subsection{Una mañana en un hogar comunitario}

Ocho am. Niños y niñas de los sectores populares van llegando a los $\mathrm{HC}$ de los barrios de Medellín. En uno de los barrios más tradicionales y populares de la ciudad, se pueden contar hasta tres y cuatro hogares comunitarios [HC] en sólo una calle, estos hogares funcionan en pequeñas casas de familia y pueden atender hasta 13 niñas y niños oficialmente.

A las ocho de la mañana se abre la puerta de los hogares para recibir a las niñas y niños quienes generalmente llegan de casas cercanas o vecinas, algunos desde más lejos y otros son llevados a los hogares desde más temprano, casi siempre porque las madres, padres o cuidadoras laboran de sol a sol, o mejor, de luna a luna, pues salen antes del primer rayo y regresan después del último destello de luz; la mayoría calle arriba, calle abajo, en lo que se conoce como el rebusque ${ }^{8}$.

Al llegar al HC los niños y niñas tienen aproximadamente una hora [de ocho a nueve] para socializar y explorar con los objetos y juguetes disponibles o para tener acceso a la televisión; es curioso que en este momento de la mañana no aparecen inconvenientes o conflictos entre ellos, cada uno puede jugar y manipular los juguetes disponibles sin mayores problemas, una interesante situación que pone en cuestión muchas de nuestras prácticas pedagógicas y estrategias didácticas soportadas por explicaciones evolutivas del desarrollo motriz y biológico; lección pedagógica acerca del valor del juego despedagogizado y de la libertad de espacio-tiempos descurricularizados para la infancia. Lenta y paulatinamente van ingresando niños y niñas de los barrios populares, mañana tras mañana a los $\mathrm{HC}$, en una jornada que va desde las ocho hasta las dieciséis horas [oficialmente], pero que en realidad, para muchos niños y niñas inicia más temprano y termina más tarde; algunas niñas y niños sólo ven los rostros de sus cuidadoras y/o familiares en la mañana cuando los despierten para llevarlos al HC. De esta manera van pasando el duelo, día a día cortando el cordón umbilical, que al iniciar la mañana parece pegarse a las patas de la televisión "interactiva", pantalla que sigue confirmando su

8 Rebusque: Así de denomina la práctica de salir a buscar [rebuscar], en medio del desempleo, una fuente laboral que permita conseguir o llevar el sustento diario a casa; fuentes laborales informales, esporádicas, momentáneas y fugaces. 
capacidad para atrapar y de paso educar a la niñez... la televisión atrapa la atención, los ánimos y sirve para mantener la tranquilidad en la sala del hogar, bajo una especie de hipnosis consentida por muchos de los que laboramos con la atención integral a la primera infancia.

A continuación, se presenta, de manera descriptiva las prácticas constitutivas de la atención a la infancia durante una mañana en los HC.

\begin{tabular}{|c|c|}
\hline PRÁCTICA [Foto Opcional] & DESCRIPCIÓN \\
\hline La bienvenida & $\begin{array}{l}\text { Consiste en un saludo por parte del o la agente educativa } \\
\text { [madre comunitaria o profesional del programa] dirigido a los } \\
\text { niños y niñas del HC. Espacio-tiempo curricularizado, } \\
\text { intervención realizada a través de canciones infantiles. Este } \\
\text { momento avisa que el día en el hogar ha comenzado, se } \\
\text { recuerda el día de la semana y se hacen algunos acuerdos de } \\
\text { comportamiento. }\end{array}$ \\
\hline El lavado de manos & $\begin{array}{l}\text { Práctica de higiene, las madres comunitarias deben recordar } \\
\text { siempre el lavado de manos antes de que los niños y niñas } \\
\text { pasen a tomar sus alimentos. Este hábito es enseñado, algunas } \\
\text { agentes educativas utilizan canciones para facilitar el } \\
\text { aprendizaje. }\end{array}$ \\
\hline La Oración & $\begin{array}{l}\text { Práctica religiosa observada en los } 10 \text { hogares comunitarios a } \\
\text { cargo e igualmente referenciada por los demás profesionales } \\
\text { del equipo. La oración se hace sagradamente antes de tomar la } \\
\text { media mañana, en ocasiones se realiza la oración junto con la } \\
\text { bienvenida. Se agradece a "papa dios" por los alimentos } \\
\text { recibidos y se refuerzan compromisos de buen } \\
\text { comportamiento. }\end{array}$ \\
\hline La media mañana & $\begin{array}{l}\text { Práctica de alimentación, para la gran mayoría este } \\
\text { complemento alimenticio representa el desayuno o el primer } \\
\text { alimento del día, a veces se alcanza a suplir esta comida que } \\
\text { según expertos es la más importante del día, pero otras veces } \\
\text { se trata sólo de un complemento [media mañana] que no }\end{array}$ \\
\hline
\end{tabular}




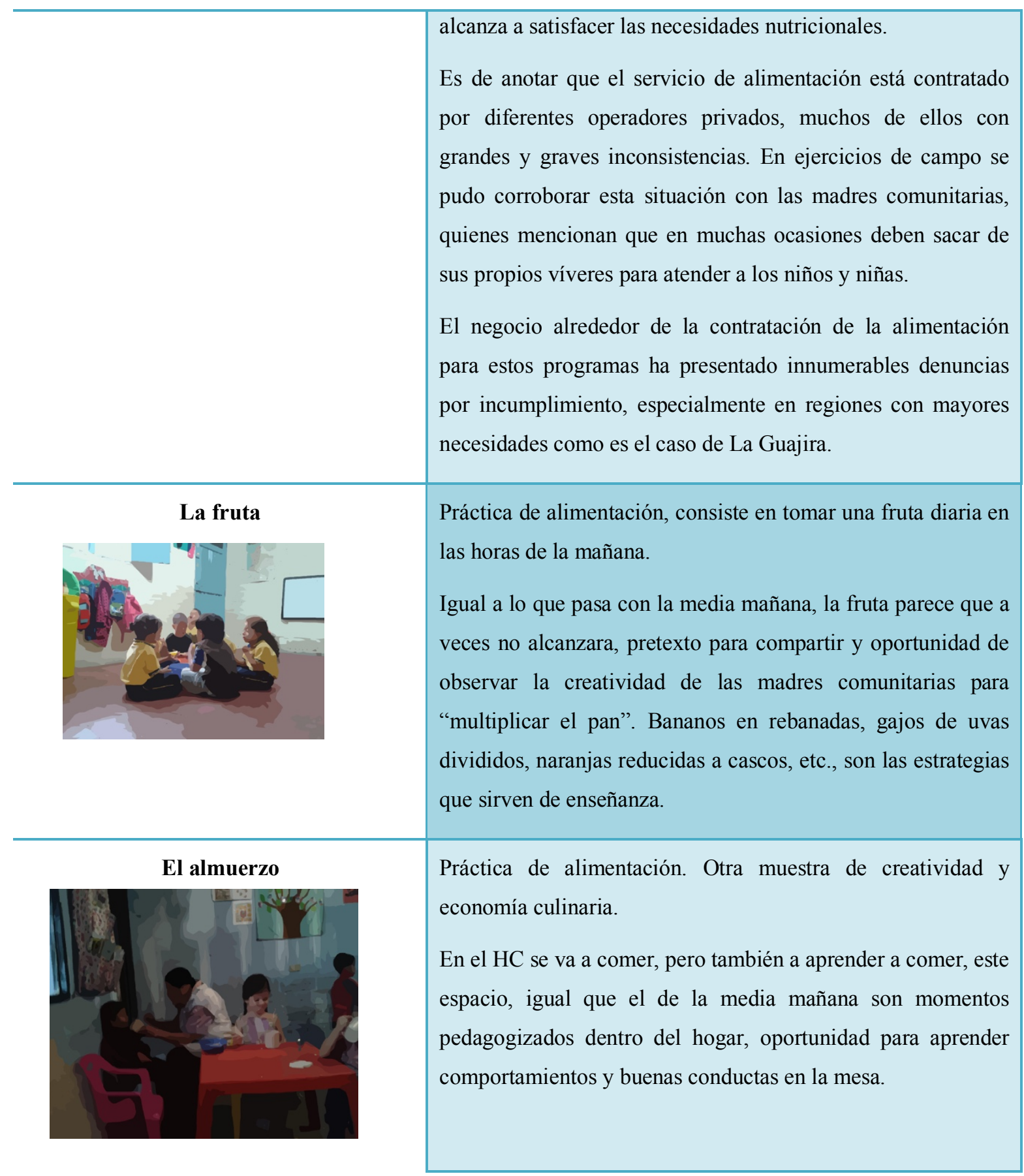

Cuadro 2. Prácticas cotidianas en una mañana dentro de un hogar comunitario.

Se podría decir que la atención integral a la primera infancia, por lo menos en estos hogares, gira en torno a la alimentación. El estómago va dictando cada uno de los espaciotiempos dentro del $\mathrm{HC}$ mientras sirve de plataforma pedagógica para transmitir hábitos higiénicos y normas de comportamiento. 
Otra de las prácticas que en su momento constituían el cotidiano de un HC tiene que ver con la intervención pedagógica del o la profesional del equipo interdisciplinario del programa itinerante. Cada $\mathrm{HC}$ contaba con el acompañamiento de un equipo constituido por un grupo de estos profesionales, equipo liderado por la educadora infantil quién era la profesional con mayor presencia en el hogar.

La intervención se realizaba generalmente después de la media mañana y antes del momento de la fruta, en este espacio-tiempo se debía realizar una actividad pedagógica dentro del HC con los niños y niñas, bien desde el área de la educación física, la pedagogía infantil, la psicología o la nutrición, según correspondiera en el cronograma del programa itinerante. El o la profesional del equipo tenía la libertad de planear una matriz metodológica mensual bajo su criterio profesional y aunque esta intervención estaba soportada desde un enfoque interdisciplinario, en la práctica, esto no lograba materializarse. Igualmente, la agente educativa madre comunitaria también debía realizar una planeación pedagógica, actividades para desarrollar con sus niños y niñas los días en los que no contara con la presencia de uno de los profesionales del equipo interdisciplinario.

Así transcurre la mañana en un $\mathrm{HC}$, espacio que, sin ser ajeno a su realidad compleja, deja ver en su enunciación la polisemia de su función; lugar de higienización, moralización, educación, protección, lúdica, disciplinamiento y afecto. A continuación, se presentan otras tareas desarrolladas por los profesionales de este programa durante su visita a los HC.

\begin{tabular}{|c|c|c|}
\hline TAREA & DESCRIPCIÓN & COMENTARIO \\
\hline RIA & $\begin{array}{l}\text { Ruta Integral de Atención a la primera infancia dispuesta } \\
\text { por el ministerio de salud. Instrumento que se espera } \\
\text { funcione como mapa para identificar las necesidades en } \\
\text { la atención integral a la primera infancia y permitir } \\
\text { ordenar la gestión intersectorial de acuerdo a las } \\
\text { necesidades. En total el instrumento [RIA] define } 184 \\
\text { atenciones, pero para efecto de este programa se debían } \\
\text { garantizar las siguientes ocho: Estado en orden del } \\
\text { registro civil; valoración y seguimiento nutricional; }\end{array}$ & $\begin{array}{l}\text { Este tipo de prácticas, aunque } \\
\text { importantes como acciones que } \\
\text { permiten caracterizar y conocer } \\
\text { la población, el entorno y el } \\
\text { contexto dentro del cual se } \\
\text { desarrollaba la intervención al } \\
\text { final terminaban por convertirse } \\
\text { en tediosos e inoficiosos } \\
\text { procedimientos administrativos, }\end{array}$ \\
\hline
\end{tabular}




\begin{tabular}{|c|c|c|}
\hline & $\begin{array}{l}\text { asistencia a consultas de desarrollo; vacunación; } \\
\text { educación inicial; acceso a libros o contenidos culturales; } \\
\text { contar con una familia en formación y afiliación a salud. } \\
\text { Estas ocho atenciones debían ser verificadas en campo } \\
\text { por los diferentes agentes educativos. }\end{array}$ & \multirow[b]{4}{*}{$\begin{array}{l}\text { Con respecto a la evaluación de } \\
\text { los riesgos de los distintos } \\
\text { hogares comunitarios y sus } \\
\text { entornos sociales, quedan } \\
\text { algunas sensaciones de } \\
\text { inconformidad e indignación, } \\
\text { pues esta labor sólo se quedaba } \\
\text { en la identificación, o mejor, en } \\
\text { la confirmación de una realidad } \\
\text { evidente: la vulnerabilidad de } \\
\text { estos espacios y la marginalidad } \\
\text { en la cual crecen y se atienden a } \\
\text { los niños y niñas de estos } \\
\text { sectores. }\end{array}$} \\
\hline CONTEO & $\begin{array}{l}\text { Contar los niños y niñas en cada visita al HC y llenar } \\
\text { formato con esta información firmado por la madre } \\
\text { comunitaria. Se dejaba registro en una planilla que luego } \\
\text { era recogida por otro funcionario. }\end{array}$ & \\
\hline $\begin{array}{l}\text { CARACTERIZACIÓN } \\
\text { DE LAS FAMILIAS }\end{array}$ & $\begin{array}{l}\text { Recolectar información en cada uno de los HC acerca de } \\
\text { las familias de los niños y niñas, quiénes la conforman y } \\
\text { en qué trabajan. Proceso articulado a la gestión de la ruta } \\
\text { RIA. }\end{array}$ & \\
\hline $\begin{array}{l}\text { EVALUACIÓN DE } \\
\text { RIESGOS }\end{array}$ & $\begin{array}{l}\text { Identificación de riesgos dentro del hogar comunitario } \\
\text { [daños físicos en la infraestructura del hogar, riesgos en } \\
\text { cuanto a conexiones eléctricas, tanques de agua, acceso a } \\
\text { la cocina y otras zonas que pudieran representar peligro, } \\
\text { objetos peligrosos, etc]. También de riesgos relacionados } \\
\text { con el contexto social [conflictividad armada en el barrio, } \\
\text { riesgos asociados a fenómenos naturales [ubicación } \\
\text { cercana a quebradas, barrancos, terrenos inestables, } \\
\text { laderas], poco o mal acceso a servicios públicos, etc]. } \\
\text { Todas estas caracterizaciones debían estar detalladamente } \\
\text { identificadas, incluso con levantamiento de croquis } \\
\text { realizado por el o la agente educativa, generalmente por } \\
\text { el agente educativo Educador[a] Físico. Al final de la } \\
\text { caracterización se debía marcar en cada hogar } \\
\text { comunitario si éste correspondía a un entorno vulnerable, } \\
\text { de ser así se disponía información en los hogares con las } \\
\text { rutas de activación de alertas [policía municipal, } \\
\text { bomberos, hospitales] y se delimitaba un punto seguro } \\
\text { dentro del hogar para responder ante alguna eventualidad } \\
\text { de peligro [enfrentamiento armado intra-urbano, desastre } \\
\text { natural, accidente]. }\end{array}$ & \\
\hline
\end{tabular}

Cuadro 3. Prácticas otras, en las márgenes de la intervención pedagógica.

\section{Legalizando una atención desatendida}


Quisiera recordar aquí algunos de los interrogantes con los que inicié esta reflexión y preguntarme nuevamente a qué intereses obedecen realmente programas y prácticas como estas, cuestiones que han emergido de la reflexión en cuanto a mi lugar como profesor, como profesional y como ciudadano, preguntas frente a las actividades que, según las políticas, debían acompañar las intervenciones pedagógicas de los diferentes agentes educativos; asuntos que hoy, con el extrañamiento, la objetivación y la evaluación de aquello que hacía me incita a la reflexión.

Cuando se está adentro de un programa público que es operado por una institución privada se pueden confundir fácilmente sus propósitos y sentidos, hasta el punto de desvirtuarse totalmente en la práctica; las preocupaciones e intereses cambian. Algo se sabe sobre este tipo de programas sociales gubernamentales, se conoce el discurso, la retórica, las leyes y los marcos teóricos que los soportan, pero poco, casi nada, de lo que pasa con éstos cuando son bajados a realidad.

Legalización de documentos, caracterización de niñas, niños y familias, garantía y restablecimiento de derechos, alimentación, salud, educación, contratación de las agentes educativas madres comunitarias, cumplimiento con los víveres, acceso de la infancia a espacios públicos de ciudad, acceso de la infancia a programas de literatura, arte y cultura, entre otros componentes que desde la política pública nacional de cero a siempre, la política pública departamental y municipal Buen Comienzo y desde el ICBF se deben garantizar, se quedan sólo en la estadística de los indicadores, algunos marcados con nuestra intervención.

Una acción sin reflexión, movida por la estimulación de sentimientos de protección, atención y cuidado infantil se convertía en la legalización de una política pública que funcionaba a medias. A los(as) profesionales, dinamizadores de un activismo ciego y acrítico, se nos encargaba sin mayores reparos legalizar encuentros no sostenidos, capacitaciones a padres y madres de familia no realizadas, atenciones a niños, niñas y madres comunitarias no satisfechas e incluso aportar con nuestros propios libros a la consolidación de bibliotecas en los $\mathrm{HC}$, en este último caso, para certificar que se cumplía con lo referente al acceso de la infancia a la literatura. Estos soportes, representaban para el 
operador o contratista privado del equipo de profesionales de agentes educativos un cheque al portador, como alguna vez me lo dijeron. Así, el papel se convierte en la evidencia y la evidencia en colilla de cobro, desdibujándose finalmente, el interés de lo público en medio del afán de lucro de lo privado.

Para ilustrar un poco la regularidad, constancia y consistencia de este programa, se puede mencionar por ejemplo que, en el año 2016, periodo del que trata esta reflexión, el programa sólo inicio su ejecución a partir del mes de julio, situación que representó que la segunda mitad del año las y los agentes educativos pasaran más tiempo ocupados con asuntos propios de la gestión que, traduciendo la gestión, en la intervención real para la que fueron contratados. Es decir, se legalizaba algo que en la acción no se cumplía en su totalidad. No se cumplía, entre otras cosas, por el desplazamiento que este tipo de tareas significaba para la intervención pedagógica.

Hoy a agosto de 2017, este programa que llegaba a los barrios marginados de la ciudad, a los HC y conectaba con la infancia de la periferia lleva sin iniciar sus acciones desde diciembre del año anterior. Su ejecución parece una "papa caliente" de la que nadie da razón. Responsabilidades repartidas entre la alcaldía municipal de la ciudad, la gobernación departamental, el ICBF y el gobierno nacional. Despachos, entidades gubernamentales y dirigentes que parecen encontrar justificación a lo injustificado o que esperan una nueva oportunidad electoral para tomar nuevamente la bandera de la protección infantil, un sentimiento colectivo que aparece cada tanto.

\section{Para la Reflexión}

Con la noción infancia de la periferia he querido dar cuenta de la marginalidad e invisibilidad de este grupo social, en especial de la infancia que crece en los sectores de mayor vulnerabilidad social. Sería ingenuo y hasta cínico pensar esta condición al margen del contexto. Sin embargo, no se trata sólo de una referencialidad geográfica de la niñez en la ciudad, sino también en las políticas sociales que se proyectan y ejecutan a su favor; en la reflexión académica y en la presencia curricular dentro de los programas de formación universitaria [específicamente de la formación del profesorado de educación física] y en general en las representaciones que como ciudadanos, profesionales y educadores tenemos 
sobre la infancia. Quizá al desnaturalizar la infancia, al pensarla dentro de coordenadas espacio-temporales [Varela, 1992] podamos descubrir un poco los significados socio culturales y políticos de la "preocupación” por su atención, protección y cuidado.

Los HC no son escuelas, no son guardería, tampoco hogares en estricto, pero son todas estas cosas a la vez, son espacios donde se juega la atención primaria y la educación de una gran parte de los recién llegados a esta ciudad, a este mundo (Arendt, 1996). El HC funciona como una matriz que alimenta, cuida, educa... protege a la infancia que crece en los focos periféricos de la vulnerabilidad social; lugares que representan una oportunidad en medio de un entorno marginado y hostil.

La infancia de la periferia crece entre dos opciones, la calle y los aprendizajes de un contexto "degradado" o el hogar comunitario y el encierro entre cuatro paredes protectoras. Por ahora la ciudad de los niños, de la que Medellín hace parte, y el acceso al espacio público como entorno educativo de las políticas públicas de atención integral a la primera infancia siguen siendo metas por alcanzar, en la explicación de Eduardo Galeano, siguen siendo una utopía ${ }^{9}$ en sectores como los aquí referenciados.

No se trata sólo de una reflexión crítica sobre las políticas, los programas y las instituciones que trabajan por la infancia, sino también la lectura autocrítica por el lugar y las prácticas de quienes finalmente somos los agentes, profesores [as], profesionales y actores encargados de traducir la gestión en acción real. Cuestionamientos que parten del reconocimiento de lo existente, del reconocimiento de los costos sociales desde los que se han gestado estos avances, pero que, en la idea de mejorar, deben siempre pasarse por la reflexión crítica, sobre todo de quienes de una u otra forma lo vivimos desde adentro.

La tercerización laboral y educativa, da oportunidad para que se pierdan las responsabilidades. Este tipo de contratación e intervención deja la práctica pedagógica a merced de una mecánica irreflexiva, por ahora sólo se ve sometida a preocupaciones valoradas en claves de desarrollo psicobiológico: índices nutricionales y curvas o medidas

9 Eduardo Galeano plantea que la utopía está en el horizonte, cuando se camina un paso hacia ella el horizonte se aleja dos pasos más. Esta condición, según el escritor, representa una oportunidad de avanzar siempre; sirve para caminar. 
tipo estándar del desarrollo motriz y cognitivo, preocupaciones higiénicas y preocupaciones de tipo administrativo y burocrático: cumplimiento con la atención [sin importar el cómo], cobertura, trazabilidad [relación directa entre la ejecución y el cronograma], etc.

Experiencias profesionales como esta permiten pensar en lo importante de la formación ética y política en los programas de formación universitaria, sobre todo en tiempos de tecnificación, instrumentalización y desprofesionalización del profesorado.

\section{Referencias bibliográficas}

Arendt, H. (1996). Entre el pasado y el futuro. Ocho ejercicios sobre la reflexión política. Barcelona: Ediciones Península.

Ariés, P. (1987). El niño y la vida familiar en el antiguo régimen. Madrid: Taurus.

Henao, O. (10 de febrero de 2017). Una mano para las madres comunitarias. El Colombiano. Consulta realizada 15 jun. 2017. http://www.elcolombiano.com/opinion/columnistas/una-mano-para-las-madrescomunitarias-AI5903389

Laiton, S., y Olmos, Y. (2013). La Protección Infantil en Colombia, una Sospecha por el Cuidado de los Niños (1960-1990) (Tesis de maestría). Colombia, CINDE Universidad Pedagógica Nacional.

Larrosa, J. (2006). Sobre la experiencia. Aloma: revista de psicologia, ciències de l'educació i de l'esport Blanquerna, 19, 87-112.

Personería de Medellin. (2016). Informe sobre la situación de los derechos humanos en la ciudad de Medellín 2015. Medellín.

Trilla, J. (2004). Los alrededores de la escuela. Revista española de pedagogía , 228, 305 324.

Varela, J. (1992). Categorías espacio-temporales y socialización escolar: del individualismo al narcisismo. Revista de Educación, 298, 7 - 29. 